\title{
Implementation of the Safe Schools Programme in the Secondary Schools of the Limpopo Province in South Africa
}

\author{
Layane Mabasa \\ School of Education, University of Limpopo, South Africa \\ thomas.mabasa@ul.ac.za
}

\section{Doi:10.5901/mjss.2014.v5n27p752}

\begin{abstract}
Several programmes and interventions have been developed to deal with challenges facing schools in South Africa. As a result, there seems to be much focus on designing and developing interventions with less emphasis on the implementation thereto. The purpose of this article is to report on a study that focused on the implementation of the Safe Schools Programme in the secondary schools of the Limpopo Province. A qualitative approach where seven schools were selected as sites was adopted for use in the study. Data were generated from observation, interviewing and documents. Analysis of data was done by developing categories. Categories developed included knowledge about the existence of the Safe Schools Programme, implementation and barriers to the implementation. Some findings from the study show that there was no implementation of the programme due to some barriers. Amongst other barriers was that schools did not get support from the Department of Education and their communities in the implementation of the Safe Schools Programme. It is concluded that lack of support, particularly from the Department of Education is an indication that the safety of learners in schools is not taken as a priority by those who are in charge of the Department. Recommendations were made.
\end{abstract}

Keywords: Implementation; Safe schools; Safe Schools Programme

\section{Introduction}

Schools in South Africa, especially after 1994, seem to be dysfunctional and unsafe (Christie, 1998; Bester and Du Plessis, 2010). They have become unsafe because of multiple forms of violence ranging from assault, rape, carrying dangerous weapons, sexual abuse, emotional abuse, burglary, vandalism, criminal offences, theft, gang- related violence, suicides, alcohol-,drug-and medication abuse (Govender, 2006), pornographic material, shootings (Vally, 2002; Khan, 2008) and bullying (The Human Rights Commission of South Africa, 2008). These forms of violence, cause unprecedented disruptions to teaching and learning (Vally, 2002). In response to this state of affairs, the government designed several programmes and interventions to resolve the problem. Amongst these were interventions such as Culture of Learning and Teaching Services (COLTS), Business Against Crime and TiisaThuto (TT) (Domingo-Swarts, 2002), The Crime Reduction in Schools Programme (CRISP) in Durban, The School Watch Programme in KwaZulu-Natal and the Safe Schools Programme (Shaw, 2001). But these interventions notwithstanding, school safety remains a mirage in most schools.

While noting the policies, frameworks and programmes that have been developed since 1994, there seems to be a problem with the implementation of many of these initiatives (Roper, 2002). It would seem that there is a tendency, in general, especially in developing countries, to focus on formulating and initiating policies, projects and programmes with less emphasis on implementation (Dyer, 1999).

\section{Rationale for the Study}

In this study, I decided to focus on the implementation of the Safe Schools Programme (Department of Education, 2002). The decision to focus on the Safe Schools Programme (Department of Education, 2002) was because of a number of reasons like: the fact that some of the staff members who were supposed to implement the programme raised concerns during our informal conversations about the success of the implementation of government programmes in general and the Safe Schools Programme (Department of Education, 2002) in particular. Concerns raised include lack of proper training for the staff who was supposed to implement the programme, mismanagement of resources by some of the staff members, lack of clear guidelines on the implementation of the programme and lack of commitment to the programme by school based managers. Furthermore, looking at the importance of the safety of learners in schools, it became an issue 
that required investigation. Teaching and learning may not effectively take place unless teachers and learners are safe. It is therefore an issue that should be treated as a priority.

\section{Theoretical Framework}

There is no single unifying theory on issues of school-based implementation of interventions aimed at dealing with school violence and safety of learners in schools (Alba and Galle, 2012). However, in their study of Implementation in schoolbased preventive interventions, Greenberg, Domitrovich, Graczyk and Zins (2005) identified two theories that can be helpful in studying school-based preventive interventions. They identified the theories as causative theory and prescriptive theory. Causative theory explains how the targeted problem develops and also informs on appropriate strategies to be selected in dealing with the problem. Prescription theory is the theory that involves the specification of essential elements of both the planned intervention and the actual implementation of the intervention. It involves the construction of a measurement system to assess the elements in the actual implementation process. Further, it also highlights the discrepancies that exist between what is planned and what actual happens during implementation. Since the study focused on the implementation of the Safe Schools Programme (Department of Education, 2002), I adopted the prescription theory. The adoption of the theory was informed by the fact that the focus was on the actual implementation of the Safe Schools Programme (Department of Education, 2002) in schools while taking the activities of the programme as presented in the plan into consideration. The plan served as a guide on what is to be expected in the implementation of the programme.

\section{Statement of the Problem}

While noting the policies, frameworks and programmes that have been developed since 1994, as already indicated, there seems to be a problem with the implementation of many of these initiatives. It appears as if implementation is viewed as being less important and as such it is not given attention. The problem is that focusing on developing programmes and other interventions, without paying attention to implementation leads to lack of knowledge in terms of the activities that are involved in the implementation process.

A review of the literature produced very little evidence of studies that focus on programme implementation in South Africa. Instead, most studies in Psychology and Social Work appear to focus on programme development and impact (Sathiparsad, 1997; Nott, 1997). Studies on safety in schools focus on different issues than issues related to the implementation of interventions in schools. For example, a study by Rossouw (2003) focuses on learner discipline in South African schools with special emphasis on educators' positive and negative reactions to learners misconduct, while a study by Joubert (2007) focuses on the examination of documents such as acts, government notices, policies, national and international law to understand concepts related to a disciplined school and the safety and security of learners in schools. Masitsa (2011) explores safety in township secondary schools in the Free State province where the study found that both teachers and learners are not safe in their schools. It is within this context that an implementation of the Safe Schools Programme (Department of Education, 2002) in the Capricorn and Waterberg Districts of the Limpopo Province was deemed important.

\section{Research Questions}

The study was done by raising the following questions:

How is the Safe Schools Programme implemented at the secondary schools of the Limpopo Province of South Africa? This question was answered by raising subsidiary questions as follows:

- Do the stakeholders know about the existence of the safe schools programme?

- Was the programme being properly implemented?

- Are there barriers to the implementation of the Safe Schools Programme?

\section{Methodology and Design}

Greene in Denzin and Lincoln (1998) indicates that research methodologies constitute frameworks of philosophical assumptions which the researcher might be having concerning the world, knowledge and ethics amongst other things. The choice of such methodologies for use in a study is influenced by several issues. In this study, the choice was influenced, as Stake (2004) indicates, by the needs of the stakeholders in the implementation of the Safe Schools 
Programme (Department of Education, 2002). They raised several issues about the implementation of the Safe Schools Programme.

Due to what has been explained, and the need to interact with the stakeholders in the setting by being involved in the day-to-day realities of the programme, the study followed an advice given by Rist to implementation researchers in Denzin and Lincoln (1998:411) when he writes that an implementation study "is best done through qualitative research". The approach helped me to interact with the participants in the study in their natural setting and enabled me to describe and understand the programme through their eyes. It also helped me to have a sense of their feelings about the implementation of the programme.

The study used a qualitative case study design. The use of a qualitative case study design was informed by the research question: How is the Safe Schools Programme being implemented at the Secondary Schools of the Lipompo Province of South Africa? Further, case study design helped me to understand the phenomenon (programme implementation) and the interpretation of meanings within context through the eyes of various participants in the study. It also helped in capturing different views of the stakeholders in the programme. This was done by being open and flexible to accommodate other opportunities and different views of different stakeholders in the Safe Schools Programme.

\subsection{Sampling/Selection of cases}

Case selection in qualitative studies is different from statistical sampling which is associated with experimental designs. In this study, a purposive selection strategy was adopted. This is a strategy which as Stake (1995:8) indicates allowed me to select schools that were helpful in getting the required data and also "hospitable" to my study.

Other principles of convenience selection were also employed during the study. They included selecting schools that were easily accessible. They are the schools where some of the participants were familiar with the researcher.

Seven schools in the Capricorn District of the Limpopo Province were selected for the study. Schools selected were designated schools A, B, C, D, E, F and G. The designation of schools as indicated was done in order to keep their anonymity for ethical reasons. School A is 104 kilometers in the southern side Polokwane whereas school B is 9 kilometers away located in the western side of the city. School $\mathrm{C}$ is 74 kilometers from Polokwane located in the southern side. School $D$ is in the south eastern side of the city. Its distance from the city is 68 kilometers. School $E$ is 22 kilometers away from Polokwane. It is located in the eastern side. School $\mathrm{F}$ is in the western side of Polokwane. It is 105 kilometers away whereas School $\mathrm{G}$ is 16 kilometers away from the city also situated in the western side. The furthest distance of the schools selected is 105 kilometers from Polokwane. All schools were also easily accessible through tarred road except school C. The school is not easily accessible due to the gravel road that has potholes. It was included in the study because it of its location and the potential it had in getting the data that would help in answering the research question.

Participants in the study included different stakeholders that were supposed to be involved in the implementation of the Safe Schools Programme (Department of Education, 2002). The following groups were identified: Principals, School Governing Bodies (SGBs), teachers, Representative Council of Learners (RCL), government officials responsible for the implementation of the Safe Schools Programme.

\subsection{Data collection}

Three methods of data collection were used. Methods used are observation, interviewing and documents. The use of the three methods is in line with Creswell's (2013:52) assertion that "Unquestionably, the backbone of qualitative research is extensive collection of data, typically from multiple sources of information." Multiple sources of information helped in triangulating the data collected which was meant to maximize the dependability and trustworthiness of the study.

I spent time in schools observing what was happening in terms of the implementation of the Safe Schools programme. That helped me to see what is happening in the setting and be able to describe the context in detail. This was done between May 2010 and June 2011. During the time, seven schools were visited for observation. Two visits were made to each of the schools. In each of the schools, an hour was spent observing what was happening in terms of the implementation of Safe Schools Programme. From the observation made in schools, there were other issues that arose which were not clear. The issues that arose amongst others included lack of clarity on whether the programme is being implemented or not; the involvement of different stakeholders in the implementation of the programme; their understanding of the programme and contextual factors that have an influence on the implementation of the Safe Schools Programme.

In order to get clarity on these issues, a specific interview technique was chosen for use. Patton (1987:109) distinguishes three kinds of qualitative interviews as "the informal conversational interview", "the general interview guide 
approach" and "the standardized open-ended interview". Initially, I intended to use both the informal conversational interview and the general interview guide. After interaction with the stakeholders in the field during observation, the informal conversational interview and the semi- structured interview were conducted.

The informal conversational interview helped me to talk with the participants on different issues about the schools in general and the implementation of the Safe Schools Programme in particular. This usually took place when we were moving around the school yard. This helped them to relax and relate issues that they could otherwise not engage within formal settings. It allowed me as Clarke and Dawson (1999); Arksey and Knight (1999); Rubin and Babbie (2010); Johnson and Christensen (2012) indicate to introduce the topic and probing questions. It was possible to make follow-up questions in situations where responses needed more explanation. Participants interviewed are Principals, School Governing Bodies (SGBs), teachers, Representative Council of Learners (RCL), government officials responsible for the implementation of the Safe Schools Programme.

Various documents related to the implementation of the Safe Schools Programme (Department of Education, 2002) were consulted. Documents consulted included: Protecting Your School From Violence and Crime: Guidelines for Principals and School Governing Bodies (Independent Projects Trust, 1999); COLTS Creative Arts Initiative (1999); Status Report for the Minister for Education (1999); Signposts for Safe Schools: Tirisano: Enabling Safe and Effective teaching and learning environments workbook (2002); Three-Year Plan and Budget for the No Crime in Schools Component of the Culture of Learning and Teaching Services (COLTS) Campaign; Safe Schools Programme; South African Schools Act (SASA, 1996); Alternatives to Corporal Punishment (Department of Education, 2000); Regulations for safety Measures at Public Schools (2001). The documents as indicated in the theoretical framework served as a guide and helped me to have an idea of the activities involved in the implementation of the Safe Schools Programme (Department of Education, 2002).

\section{Ethical Consideration}

Ethical issues were taken into consideration during the different phases of the study. The participants were informed about the study and that participation was voluntary. Their identities were also kept anonymous in order to protect them from effects as a result of information appearing in the public. The confidentiality of settings was ensured by using pseudonyms - School A, School B, School C, School D, School E, School F and School G - to disguise the research sites (British Educational Research Association, 2011).

\section{Data Analysis and Presentation of Results}

Preliminary data analysis was done during fieldwork. This was done in line with Grbich's (2013) advice that data need to be checked and tracked to see what is coming out of it and then identifying areas that require a follow up and questioning where the information collected was leading to. This was done within the prescriptive theoretical framework where the documents especially the implementation plan served as a guide.

Notes on things that stuck out in the field were taken. Write ups were done immediately after the interviews and observations. Data gathered from interviews were analysed by looking at the responses of each participant interviewed. Interviews were tape-recorded and thereafter transcribed into texts. Since the length of interviews was on average 20 minutes, this resulted in the length of interview transcripts to be five to six pages per transcript. After mass of data was collected, they had to be arranged systematically by classifying and categorizing them (Creswell, 2007; Silverman, 2011; Bazeley, 2013). Categories in this study which were generated from the data and the research question included: knowledge about the existence of the Safe Schools Programme, implementation of the programme in schools, and factors serving as barriers to the implementation of the programme.

\section{Discussion}

Looking at the results, there seems to be strong evidence indicating that there was no implementation of the Safe Schools Programme (Department of Education, 2002) at the target schools. This becomes evident when looking closely at the identified categories.

\subsection{Knowledge about the existence of the programme}

Looking at the results, it is evident that stakeholders differ in terms of their knowledge about the existence of the 
programme. In schools A, C, E and F the principals knew about the Safe Schools Programme. On the contrary, in schools B, D and G principals did not know about the programme. In school B, what the principal knew about was a certain programme that was run by a non-governmental organization known as Link Community Development. This was in reference to the Child Friendly Schools programme.

In schools A, C, D and G the SGBs knew about the programme, whereas in schools B, E and F they did not know about the programme. In schools $A, D$ and $G$, the teachers knew about the programme, whereas in schools $B, C, E$ and $F$ teachers did not know about the programme. In school $B$, the programme which the teachers knew about is the Child Friendly Schools programme. The RCLs, in schools D, F and G, knew about the programme. In schools A, B, C, and E they did not know about the programme.

The picture that emerges is that principals and SGBs seemed to know about the programme whereas teachers and RCLs did not know about it. This may be as a result of the way in which the Department of Education communicates with schools. They usually communicate with principals who in turn have to communicate with the SGBs, especially the parent component. This was emphasized by teachers in school D when they were asked about whether they knew safe schools programme policies or not. They stated that "No, perhaps it might be in the office of the principal. We never saw it. So we do not know about it."

According to the SASA, teachers and learners are supposed to be part of the SGBs. They are supposed to get information through their representatives in the SGB. This may be indicative of the manner in which the schools operate where the principal and the SGBs operate without involving other stakeholders. This may mean that the principal is working with the parent component of the SGB excluding the other stakeholders.

\subsection{Implementation of the programme in schools}

Looking at the implementation of the programme in these schools, it is evident as different stakeholders indicate that there was no implementation of the programme. Those who said they were implementing the programme, were also not sure about it. Those who were not sure about the implementation of the programme expressed their uncertainty in different ways, for example the principal in school B expressed it thus:

We are trying although it is not $100 \%$ as it is supposed to be, but the little bit that we do. We try. We lock the gates during the teaching and learning hours and access to the school premises is strictly controlled. We try to check who gets in and what the purpose of the visit is. This is to make sure that learners are protected when they are in the school premises as well as educators they should always be protected when they are in the school premises. Almost everybody like yourself, when you visit the school, you must feel safe when you are within the school premises.

Teachers in the same school were also not certain. This was evident when they stated that: We think we can say we are partially involved because sometimes we search learners for weapons in the classes. Even the police are involved. We have adopted a police person through adopt-a-cop.

The RCL in school A just indicated that they were not sure. Even though they were involved in activities related to the safety of learners, but they were not sure as to whether that is part of the Safe Schools Programme or not.

Others seemed to have mistaken Safe Schools Programme with other programmes which were running in schools during the time of the study. This became evident when looking at some of the responses. The RCL in school $G$ highlighted this when they responded by indicating that:

We are involved in the implementation of National Institute for Crime Prevention and Reintegration of Offenders (NICRO) programme. We help NICRO by searching learners at the gate. We also help by seeing to it that learners are not loitering around the school yard and they are always in a school uniform. We also focus on the issue of those who coming late to school. The school uniform is very important on issues related to safety because it is not easy to carry a weapon when you are in a school uniform. We are not that worried. But if learners are not in a school uniform, they become very aggressive. They wear these very expensive labels and become jealous of each other. This also leads to a situation where they fight for girlfriends. Those who wear expensive clothes take other people's girlfriends and they start fighting. That is the reason why in this school we do not encourage casual days because learners end up fighting.

Teachers in schools $D$ and $E$ referred to other programmes that they were implementing instead of the Safe Schools Programme. Teachers in school D said "No, we only implement the Child Friendly Schools programme", whereas teachers in school $\mathrm{E}$ expressed thus:

If that refers to the safety measures that we are implementing as a school, there are some of the measures that we are 
taking. We have a security guard who is looking after the property. He also searches learners in the morning when they enter through the gate. Again we are working jointly with the Mankweng police office that is the South African Police Services (SAPS). We have adopted a cop. There is this programme called adopt-a- cop. We are able to liaise with a particular police officer to help us. In some cases we have problems with learners, even if it is not that serious we are able to phone him and he responds to those cases.

These responses might be indicating that the Safe Schools Programme (Department of Education, 2002) is not being implemented in schools. Furthermore, they might also be indicative of the fact that even if the programme is not being implemented, there are some initiatives that schools are taking in dealing with safety issues in schools. This is reflected when they highlight activities that they are involved in which have something to do with safety issues in schools.

The manager of the Safe Schools Programme in the Department of Education in Limpopo, South Africa, also highlighted the issues on the lack of implementation of the Safe Schools Programme. According to the manager, there is no implementation. This is reflected in the response that was given when it was stated that:

\begin{abstract}
The challenge we have on the organizational structure of this department, has been a problem in terms of delivery of services. That is, first you need to have an organ to be able to discharge this responsibility. From the Department of Education in Limpopo, this task was only acknowledged at the organizational structure in 2005. There was nobody to discharge it. I had to act and assist from 2005 to 2009. I was only appointed last year (2009). Now this has become my key responsibility area to focus on. The unfortunate set up is from the Province's side, it will be me only. I needed to have tentacles; you know the leg to stand on. I needed to have support staff in the office, support in the district, and support to the circuit level so that we are able to reach the schools. So it is not possible. It is not possible. It has not happened and now it is 16 to 18 months. So our implementation capacity is very limited.
\end{abstract}

This response might be indicative of the lack of support to the section that is supposed to coordinate the implementation of the programme. This might be one of the reasons for this apparent lack of implementation of the programme in schools. This may mean that the programme exists as outlined in paper only, but without implementation because according to the documents I was given, implementation was supposed to have started in the year 2001/2002. Lack of implementation resonates with what Rembe (2005) found in the Eastern Cape when he indicates that absence of support from the Department of Education is a major obstacle to the implementation of programmes. This means that even if the schools are willing and committed to the implementation of a programme, without assistance from the Department of Education, they may not be able to implement it.

\title{
9.3 Barriers to the implementation of the programme
}

On the issue of barriers to the implementation of the Safe Schools Programme, stakeholders expressed different views. To them factors that are hindering the implementation include lack of support from the community; lack of training on issues related to safety; taverns, shebeens and beer halls near the schools; lack of resources and finances; lack of security guards at the gates; drugs; members of the community who are not cooperative; and lack of information about the Safe Schools Programme.

It is interesting to note that some of the learners are also seen as part of the barrier to the implementation of the programme, particularly by the SGB in School D, by the RCLs in Schools D, F and G, and by the principals in Schools F and $\mathrm{G}$. The teachers in School $\mathrm{C}$ expressed it when they said:

There are problems. As we indicated learners come from different families. Other learners you can see just by mere looking at them. When they come to school with a weapon, they do not realize that what they have is wrong. You can see that they come from different families. To mentor a person who is not well guided at home is difficult. We as educators are just secondary parents.

The perception of certain learners held by some of the other stakeholders is pertinent. They view them as troublemakers, which might be true as other learners like the RCLs also view them as problematic.

Lack of support from the community is also seen as one of the factors that are hindering the implementation of the Safe Schools Programme. This may be due to their past experiences where there has been not much community support for other projects. It is crucial for the communities to support the schools but this is not always the case. This seems to be a universal problem, as Stake (1995:138) also encountered this while doing a case study in the Harper School in the United States of America (USA): 
Community involvement in Harper School was not high. Only a few parent volunteers worked with teachers. It was even difficult to get Local School Council members to come to council meetings. In the words of Mattie Mitchell, teacher and school community representatives, 'Who wants to make decisions? Who is ready to make decisions? Not many.'

This may also be indicative of the importance of community support for schools to succeed in their work. It makes things easier for the schools to operate. This is in line with Khan's (2008) observation in a baseline study that was conducted to understand what was happening in schools. One of the recommendations was that schools, as an integral part of the community, need to have partnerships with stakeholders in communities.

Some of the stakeholders did not feel there would be any obstacles. These were the teachers in School E, and the principal of School C. This may be due to the fact that because they are in authority, they would facilitate its implementation.

Schools B and D, located in the township, see drugs as a potential obstacle to implementation of the Safe Schools Programme. This concern reflects problems in the surrounding neighbourhoods, as Schools A, C, E, F and G all list taverns, beer halls and shebeens as potential stumbling blocks.

\section{Conclusion}

The article has established that there is no implementation of the Safe Schools Programme. Lack of implementation is as a result of several barriers. This article has attempted to identify some of them. They seem to focus on the learners, the Department of Education and the communities where the schools are situated. Learners from a violent community become violent in schools and that leads to them becoming a barrier to the implementation of the Safe Schools Programme Schools do not seem to get enough support from the Department of Education and the communities. Lack of support from the Department might be due to lack of commitment to the implementation of the programme in schools as highlighted by the official from the department of Education. Furthermore, this might be indicative of the fact that the safety of learners is not taken as a priority by those who are in charge of the Department of Education. This seems to be a major barrier.

\section{Recommendations}

The article provides some suggestions as to what can be done in trying to deal with lack of implementation due to the barriers identified. Suggestions include making it a point that: 1) the Department of Education and communities where schools are located should give more support to schools on issues related to the safety of learners and the implementation of the Safe Schools Programme; 2) the Department of Education and communities should deal with the issue of taverns and shebeens that are near the school premises; 3) parents be helped to be responsible and not use learners in selling drugs; 4) the participants be trained before the implementation of any programme related to the safety of learners in schools. This will help them to cope and have a positive attitude towards implementation; 5) more resources be allocated on issues of safety and security in schools; 6 ) the safety of learners in schools be taken as a priority in order to create an environment conducive for effective teaching and learning.

\section{References}

Alba, D., \& Galle, R. K. (2012). Paper presented at the 43rd annual meeting of the NortheasternEducational Research Association. RockHill, C T. [Online] Available: http://digitalcomm (March 4, 2012).

Arksey, H., \& Knight, P. (1999). Interviewing for Social Scientists. London: Sage.

Bazeley, P. (2013). Qualitative data analysis: Practical strategies. London: Sage.

Bester, S., \& Du Plessis, A. (2010). Exploring a secondary school educator's experiences of school violence: a case study. South African Journal of Education, 30, 203-229.

British Educational Research Association, (2011). Ethical Guidelines for Education Research. [Online] Available: www. Bera.ac.uk (March 21, 2014).

Christie, P. (1998). Schools as (Dis) Organisations: the 'breakdown of the culture of learning and teaching' in South African schools. Cambridge Journal of Education, 28, 283-300.

Clarke, A., \& Dawson, R. (1999). Evaluation Research: An Introduction to Principles, Methods and Practice. London: Sage.

COLTS Creative Arts Initiative, (1999). Issue 1. Pretoria.

Creswell, J. W. (2007). Qualitative Inquiry \&Research Design: Choosing among five approaches. (2nd ed.). Thousand Oaks: Sage.

Creswell, J. W. (2013). Qualitative Inquiry and Research Design: Choosing among Five Approaches. (3rd ed.). Thousand Oaks: Sage.

Department of Education, (2000). Alternatives to Corporal Punishment. Pretoria: Department of Education. 
Department of Education, (2002). The Safe Schools Program. Pretoria: Department of Education.

Domingo-Swarts, C. (2002). Towards a sustainable model for Safer Schools in South Africa: An implementation Framework for Gauteng Schools. A Paper presented at "The Role of Schools in Crime Prevention Conference". Carlton Crest Hotel, Melbourne Australia.

Dyer, C. (1999). Researching the Implementation of Educational Policy: a backward mapping approach. Comparative Education, 35, 4561.

Govender, P. (2006). Huge plan to beef up school security. Sunday Times, October 29.

Grbich, C. (2013). Qualitative data analysis: An introduction. (2nd ed.). London: Sage.

Greenberg, M. T., Domitrovich, C. E, Graczyk, P. A., \& Zins, J. E. (2005). The Study of Implementation in School-Based Prevention Interventions: Theory, Research, and Practice, 3. DHHS Pub. No. (SMA) Rockville, MD Centerfor Mental Health Services, Substance Abuse and Mental Health ServicesAdministration. [Online] Available: www.sahsa.gov (March 4, 2014).

Greene, J. C. (1998). Qualitative Program Evaluation: Practice and Promise. In N. K Denzin, \& Y. S. Lincoln (Eds.), Collecting and Interpreting Qualitative Materials (pp. 372-399). Thousand Oaks: Sage.

Independent Projects Trust. (1999). Protecting Your School from Violence and Crime: Guidelines for Principals and School Governing Bodies. Durban: IPT.

Johnson, B., \& Christensen, L. (2012). Educational Research: Quantitative, Qualitative, and mixed Approaches. (4 ${ }^{\text {th }}$ ed.). Thousand Oaks: Sage.

Joubert, R. (2007). South African approach to school safety: Can it succeed? Journal of Education, 42, 107-124. [Online] Available: http://www.aca (January 7, 2014).

Khan, F. (2008). Building School Safety: The Hlayiseka Project- A Whole School Approach. Centre for Justice and Crime Prevention. CJCPIssue Paper, 6.

Masitsa, M. G. (2011). Exploring safety in township secondary schools in the Free State province. South African Journal of Education, 31, 163-174.

Nott, B. M. (1997). The Impact of a social skills training programme on interracial contact at an integrated secondary school. M.A dissertation. Potchefstroom: Potchefstroom University for Christian Higher Education.

Patton, M.Q. (1987). How to Use Qualitative Methods in Evaluation. Newbury Park: Sage.

Regulations for safety measures at Public Schools. (2001). Government Gazette, 22754. Pretoria: Government Printers.

Rembe, S. W. (2005). The Politics of Transformation in South Africa: An evaluation of education Policies and their implementation with particular reference to the Eastern Cape Province. PhD thesis. Rhodes University.

Rist, R. C. (1998). Influencing the Policy Process with Qualitative Research. In N. K. Denzin, \& Y. S. Lincoln (Eds.), Collecting and Interpreting Qualitative Materials (400-424). Thousand Oaks: Sage.

Roper, M. (2002). Kids first: approaching school safety. [Online] Available: http://www.iss.co.za/PUBS/Books/CrimePreventionPartner/ Chapter 6 (August 21, 2005).

Rossouw, J. P. (2003). Learner discipline in South African public schools-a qualitative study. Koers, 68, 413-435.

Rubin, A., \& Babbie, E. (2010). Essential Research Methods for Social Work. Belmonts, USA: Brooks/Cole, Cengage Learning.

Sathiparsad, R. (1997). The development and evaluation of a conflict resolution programme: the school as context. M.A. dissertation. Natal: University of Natal.

Shaw, M. (2001). Promoting Safety in Schools: International Experience and Action. Bureau of Justice Assistance Monograph. USA. [Online] Available: http://www.ncjrs.org/pdffiles. (September 20, 2005).

Signposts for Safe Schools: Tirisano, Enabling Safe and Effective teaching and learning environments. (2002). Pretoria: Department of Education.

Silverman, D. (2011). Interpreting qualitative data: A guide to the principle of qualitative research (4th ed). London: Sage.

South African Schools Act, (1996). Government Gazette, 17579. Pretoria: Government Printers.

Stake, R. E. (1995). The Art of Case Study Research. London: Sage.

Stake, R. E. (2004). Standards-Based \& Responsive Evaluation. Thousand Oaks: Sage.

Status Report for the Minister for Education. (1999). Pretoria: Department of Education.

The Human Rights Commission of South Africa. (2008). Report on School-based Violence. Pretoria. [Online] Available: http://edulibpretoria.wordpress.com (March 16, 2012).

Vally, S. (2002). Violence in South African Schools. Current Issues in Comparative Education, Teachers College; Columbia University. [Online] Available: http://www.tc.columbia.edu/D5BA01E0-70C8-407B (June 9, 2012). 